\title{
Hydrofluoric acid etching of dental zirconia. Part 1: etching mechanism and surface characterization.
}

Quentin Flamant $^{1,2, *}$, Fernando García Marro ${ }^{1,2}$, Joan Josep Roa Rovira ${ }^{1,2}$ and Marc Anglada ${ }^{1,2, *}$

${ }^{1}$ Department of Materials Science and Metallurgical Engineering, Universitat Politècnica de Catalunya, Av. Diagonal 647, 08028 Barcelona, Spain.

${ }^{2}$ Center for Research in Nano-Engineering, CRNE, Universitat Politecnica de Catalunya, C. Pascual i Vila, 15, 08028 Barcelona, Spain.

* Corresponding Authors

E-mail: quentin.flamant@upc.edu

Phone number: +34 934054452

E-mail: marc.j.anglada@upc.edu

Phone number: +34934016701

Fax number: +34 934016706

\section{Abstract}

Rough surfaces have been shown to promote osseointegration, which is one of the keys for a successful dental implantation. Among the diverse treatments proposed to roughen zirconia, hydrofluoric acid (HF) etching appears to be a good candidate, however little is known about this process. In this work, the effect of HF concentration and etching time on the surface topography and chemistry of yttria-stabilized zirconia was assessed. Besides, to understand the etching mechanism, the reaction products present in solution and on the surface were characterized. The results indicate suitable parameters for a fast and uniform roughening of zirconia. The formation of adhered fluoride precipitates on the surface is reported for the first time and highlights the importance of cleaning after etching. Finally, it is shown that monitoring the time allows controlling the surface roughness, smooth-rough transition and fractal dimension, which should make possible the fabrication of implants with an optimal topography.

Keywords: Zirconia, Hydrofluoric, Etching, Dental, Roughness 


\section{Introduction}

Yttria-stabilized tetragonal zirconia polycrystals (Y-TZP, short: zirconia) are biocompatible and exhibit the best combination of strength and toughness of singlephase oxide ceramics. They were introduced as biomaterials in the end of the 1980s to overcome the limitations of alumina in the field of orthopedics [1]. While monolithic zirconia has been almost abandoned for orthopedic applications, in the last decade its use in restorative dentistry has been growing fast [2]. In particular, its good esthetics, high resistance to corrosion and the absence of allergic reaction make zirconia a good candidate to replace titanium for the fabrication of dental implants [3]. However, some authors reported a higher failure rate and a higher marginal bone loss when comparing zirconia to titanium. According to them, the use of zirconia implants does not appear recommendable at the moment except for specific cases (e.g. allergy to titanium), and there is a need for further research before generalizing their clinical use [4,5].

The key to solve the problem of bone loss mentioned above is to achieve a good osseointegration, which depends on numerous parameters such as surface topography and chemistry [6]. In particular it has been shown that rough surfaces exhibit a better bone response than smooth ones, and that the combination of micro- and nano-scale roughness could have synergistic effects [7-9]. Nevertheless, what is the optimal roughness for a dental implant remains unclear [8,9]. On the other hand, a complementary approach to the classical roughness parameters calculation is to perform a fractal analysis. It has been demonstrated that osteoblastic cells proliferation and adhesion is strongly correlated to fractal parameters [10]. There is therefore a strong interest in developing processes which allow controlling the roughness and the fractal dimension of a surface. 
Among the different surface chemical treatments already experimented in the literature to achieve this purpose, hydrofluoric acid (HF) etching appears to be a good candidate. Although other chemicals, such as hypophosphorous acid or an equimolar mixture of potassium hydroxide and sodium hydroxide, have been reported to successfully etch Y-TZP $[11,12]$, HF presents the advantage to be a fast etchant at room temperature. More importantly, Gahlert et al. evidenced that HF etching of zirconia implants enhances bone apposition resulting in high removal torque values [13]. Besides, HF etching can be successfully associated to sandblasting. Ito et al. showed that the combination of both treatments leads to an increase in the proliferation rate and expression of ALP activity of osteoblast-like cells (MC3T3-E1) [14] and Bergemann et al. found recently that it enhanced the human primary osteoblast maturation [15]. Additionally, the incorporation of fluoride at the surface could enhance osteoblastic differentiation and interfacial bone formation, as it does for titanium [16]. Finally, zirconia dental implants with acid etched surface are already commercialized (CeraRoot implants with ICE ${ }^{\mathrm{TM}}$ surface) and apparently have shown a similar or higher success rate as compared to titanium implants after five years of follow-up [17].

Despite of numerous studies in which HF has been used for the etching of Y-TZP, to the best of the knowledge of the authors, very little is known about the chemical reaction involved. Besides, the influence of parameters such as time and concentration is not documented. The objectives of the present work are therefore to determine suitable conditions for a fast and uniform roughening of dental zirconia, to provide a complete surface characterization with a special emphasis on topography and to contribute to the understanding of the etching mechanism. Questions related to the influence of etching on the mechanical properties and long-term reliability are treated in a second article [18]. 


\section{Materials and methods}

\subsection{Zirconia disks preparation}

Commercial 3Y-TZP powder (TZ-3YSB-E Tosoh Co., Japan) was cold isostatically compacted under pressure of $200 \mathrm{MPa}$ in a cylindrical mold for producing a green body, and then sintered in an alumina tube furnace at $1450{ }^{\circ} \mathrm{C}$ for two hours $\left(3{ }^{\circ} \mathrm{C} / \mathrm{min}\right.$ heating and cooling rates), as described in previous work [19]. The sintered ceramic cylinders were cut into specimens in the form of disks ( $2 \mathrm{~mm}$ thick, $9 \mathrm{~mm}$ diameter), which were ground and polished down to a $3 \mu \mathrm{m}$ diamond suspension. The samples were then successively cleaned for five minutes with acetone, ethanol and deionized water (DI water) in an ultrasonic bath in order to remove contaminants. The polishing step, which is not likely to be part of the processing for a commercial implant, was introduced in order to facilitate the surface characterization. It was assumed that the effects of etching on a machined and annealed surface or on a sintered surface would be comparable.

\subsection{Chemical etching}

Concentrated HF (Hydrofluoric Acid 40\% QP Panreac, Spain) was used to prepare aqueous solutions with respective mass concentrations of $5 \%, 20 \%$ and $40 \%$. Etching was performed at room temperature on zirconia disks in high-density polyethylene flasks. The volume of acid was $1 \mathrm{~mL}$ by sample. The disks were placed with the polished side upwards. Just after being removed from HF, they were rinsed with DI water in order to stop the reaction. Unless otherwise specified, after etching samples were cleaned twice ten minutes with fresh DI water in an ultrasonic bath in order to remove any remaining product of the reaction from the surface. 


\subsection{Preliminary study: determination of adequate etching conditions}

A preliminary study was carried out to determine which combinations of concentration and time were more suitable to achieve rapidly an appropriate roughness on the zirconia surface. One ultrasonically cleaned sample was used for each condition. Atomic Force Microscopy (AFM Veeco Dimension 3100) in tapping mode and White Light Interferometry (WLI, Veeco Wyko 9300NT) were used in order to characterize the topography at different scales. AFM measurements were performed on $50 \mu \mathrm{m} \times 50$ $\mu \mathrm{m}$ areas (resolution: $512 \times 512$ pixels) and WLI measurements were performed on 150 $\mu \mathrm{m} \times 150 \mu \mathrm{m}$ areas (stitching of 4 images acquired at magnification 50x, resolution: $758 \times 758$ pixels). The roughness analysis of the data from AFM and WLI was performed using Veeco's Vision ${ }^{\circledR}$ software. Tilt was corrected and a robust short wavelength pass Gaussian filter (cut-off wavelength: $10 \mu \mathrm{m}$ ) was applied to the data in order to separate waviness from roughness. Then the $3 \mathrm{D}$ roughness parameters $\mathrm{S}_{\mathrm{a}}, \mathrm{S}_{\mathrm{z}}$ and $\mathrm{S}_{\mathrm{dr}}$ were determined (for definitions, see Table 2).

The mass loss per initial external sample area and the roughness parameters were determined as a function of concentration and etching time. Based on this preliminary study the main part of this work was focused on the etching with HF $40 \%$ for times between zero and two hours. The reasons for this choice will be discussed later.

Table 1. Applied restrictions for the calculation of molecular formulas from ESI-FTMS spectra.

\begin{tabular}{|c|c|c|}
\hline Isotope & Minimum number & Maximum number \\
\hline${ }^{16} \mathrm{O}$ & 0 & 15 \\
\hline${ }^{12} \mathrm{C}$ & 0 & 5 \\
\hline${ }^{1} \mathrm{H}$ & 0 & 30 \\
\hline${ }^{14} \mathrm{~N}$ & 0 & 5 \\
\hline${ }^{89} \mathrm{Y}$ & 0 & 10 \\
\hline${ }^{90} \mathrm{Zr}$ & 0 & 10 \\
\hline${ }^{19} \mathrm{~F}$ & 0 & 10 \\
\hline
\end{tabular}


Table 2. Description of the 3D roughness parameters used in this study [20-22].

\begin{tabular}{|c|c|c|c|}
\hline Symbol & Category & Parameter & Description \\
\hline $\mathrm{S}_{\mathrm{a}}$ & Amplitude & Average roughness & Average of height values. \\
\hline $\mathrm{S}_{\mathrm{q}}$ & Amplitude & RMS roughness & Standard deviation of height values. \\
\hline $\mathrm{S}_{\mathrm{sk}}$ & Amplitude & Skewness & $\begin{array}{l}\text { Degree of symmetry of the surface } \\
\text { heights about the mean plane. The } \\
\text { sign of } S_{\mathrm{sk}} \text { indicates the } \\
\text { preponderance of peaks }\left(\mathrm{S}_{\mathrm{sk}}>0\right) \text { or } \\
\text { valley structures }\left(\mathrm{S}_{\mathrm{sk}}<0\right) \text {. }\end{array}$ \\
\hline $\mathrm{S}_{\mathrm{ku}}$ & Amplitude & Kurtosis & $\begin{array}{c}\text { Sharpness or flatness of the height } \\
\text { distribution curve. } \\
\mathrm{S}_{\mathrm{ku}}=3 \text { : Gaussian height distributions } \\
\mathrm{S}_{\mathrm{ku}}<3 \text { : "broad" height distributions } \\
\mathrm{S}_{\mathrm{ku}}>3 \text { : "narrow" height distributions }\end{array}$ \\
\hline $\mathrm{S}_{\mathrm{z}}$ & Amplitude & Ten point peak-peak height & $\begin{array}{l}\text { Average difference between the five } \\
\text { highest peaks and five lowest valleys. }\end{array}$ \\
\hline $\mathrm{S}_{\mathrm{al}}$ & Spatial & Fastest decay length & $\begin{array}{l}\text { The shortest spatial distance in which } \\
\text { the autocorrelation function decreases } \\
\text { to } 0.2 \text { of its value. }\end{array}$ \\
\hline $\mathrm{S}_{\mathrm{tr}}$ & Spatial & Texture aspect ratio & $\begin{array}{l}\text { Measure of isotropy or anisotropy of } \\
\text { surface topography. }\end{array}$ \\
\hline $\mathrm{S}_{\mathrm{ds}}$ & Spatial & Density of summits & Number of summits per unit area. \\
\hline $\mathrm{S}_{\mathrm{dr}}$ & Hybrid & Developed interfacial area ratio & $\begin{array}{l}\text { Percentage of additional surface area } \\
\text { contributed by the texture as } \\
\text { compared to an ideal plane the size of } \\
\text { the measurement region. }\end{array}$ \\
\hline $\mathrm{S}_{\mathrm{dq}}$ & Hybrid & RMS gradient & $\begin{array}{l}\text { RMS value of the surface slope } \\
\text { within the sampling area. }\end{array}$ \\
\hline $\mathrm{S}_{\mathrm{sc}}$ & Hybrid & Mean summit curvature & $\begin{array}{l}\text { Average of the principal curvature of } \\
\text { the summits. }\end{array}$ \\
\hline $\mathrm{S}_{\mathrm{bi}}$ & Functional & Bearing index & $\begin{array}{l}\text { Measure, relative to } S_{q} \text {, of the surface } \\
\text { height at the } 5 \% \text { bearing area ratio. }\end{array}$ \\
\hline $\mathrm{S}_{\mathrm{ci}}$ & Functional & Core fluid retention index & $\begin{array}{l}\text { Measure, relative to } \mathrm{S}_{\mathrm{q}} \text {, of the volume } \\
\text { (for example, of a fluid filling the } \\
\text { core surface) that the surface would } \\
\text { support from } 5 \%-80 \% \text { of the } \\
\text { bearing ratio. }\end{array}$ \\
\hline $\mathrm{S}_{\mathrm{vi}}$ & Functional & Valley fluid retention index & $\begin{array}{l}\text { Measure relative to } S_{q} \text { of the volume } \\
\text { that the surface would support from } \\
80 \% \text { to } 100 \% \text { of the bearing ratio. }\end{array}$ \\
\hline $\mathrm{S}_{\mathrm{m}}$ & Functional & Surface material volume & $\begin{array}{c}\text { Amount of material contained in the } \\
\text { surface peaks from } 0 \% \\
\text { to } 10 \% \text { of the bearing area ratio. }\end{array}$ \\
\hline$S_{c}$ & Functional & Surface core void volume & $\begin{array}{l}\text { Volume that the surface would } \\
\text { support from } 10 \%-80 \% \text { of the } \\
\text { bearing ratio. }\end{array}$ \\
\hline $\mathrm{S}_{\mathrm{v}}$ & Functional & Surface void volume & $\begin{array}{l}\text { Volume that the surface would } \\
\text { support from } 80 \%-100 \% \text { of the } \\
\text { bearing ratio. }\end{array}$ \\
\hline
\end{tabular}




\subsection{Analysis of the etching solution}

In order to identify the soluble products of the reaction, $1 \mathrm{~mL}$ of the solution resulting from the etching of a zirconia disk with $\mathrm{HF} 40 \%$ was evaporated. The dry residue was dissolved in $1 \mathrm{~mL}$ of DI water with $0.1 \%$ of formic acid $(\mathrm{HCOOH})$. Electrospray Ionization Fourier Transform Mass Spectrometry (ESI-FTMS) of the resulting solution was carried out on a LTQ Orbitrap ${ }^{\mathrm{TM}}$ Velos mass spectrometer coupled with a Thermo Scientific Accela ${ }^{\mathrm{TM}}$ High-Performance Liquid Chromatography system. The solution was introduced by the flow injection analysis method (flow rate: $100 \mu \mathrm{L} / \mathrm{min}$, mobile phase: $\mathrm{H}_{2} \mathrm{O} / \mathrm{CH}_{3} \mathrm{CN}(1: 1)$ with $0.1 \%$ of formic acid, injected volume: $5 \mu \mathrm{L}$ ). Mass spectra were acquired in both positive and negative mode. For the calculation of molecular formulas the restrictions detailed in Table 1 were applied.

\subsection{Analysis of the etching products}

To understand the etching mechanism and to identify the precipitates which formed during the treatment, zirconia disks were immersed for different times in HF $40 \%$. To avoid removing the reaction products from the surface, after etching the samples were not subjected to sonication but only rinsed with DI water. In the rest of this work, this state of the surface will be referred to as "as etched".

The "as etched" surfaces were observed by Scanning Electron Microscopy (SEM). Energy Dispersive X-ray Spectroscopy (EDS) was used for the elemental analysis of the etching products. To determine the elemental composition and the chemical state of the surface, X-ray photoelectron spectroscopy (XPS) was performed with a SPECS system equipped with an Al anode XR50 source operating at $150 \mathrm{~W}$ and a Phoibos $150 \mathrm{MCD}-9$ detector XP. Spectra were recorded with pass energy of $25 \mathrm{eV}, 0.1 \mathrm{eV}$ steps and a pressure below $7.5 \times 10^{-9}$ mbar. Binding energies were referred to the adventitious $\mathrm{C} 1 \mathrm{~s}$ signal and background was subtracted. The identification of the local bonding 
environment of each element was performed by comparing the experimental peak positions with the data from the NIST Standard Reference Database 20, Version 4.1 (http://srdata.nist.gov/xps/).

Additionally, one sample was immersed for two hours in HF $40 \%$ and ultrasonically cleaned. A droplet of the DI water used for the sonication was evaporated and the dry residue was observed by SEM, EDS, and Transmission Electron Microscopy (TEM).

\subsection{Surface characterization}

To assess the effect of etching on the surface properties, a complete chemical and topographical characterization was carried out on samples etched in HF $40 \%$.

The surface morphology was observed by SEM and the elemental composition was determined by EDS. An XPS analysis similar to the one described in Table 2 allowed to quantify the elements constituting the first nanometers of the surface and to determine their chemical state.

Following the same methodology as described in 2.3, AFM and WLI measurements were performed on respectively three and ten samples per experimental point. From these measurements, the $3 \mathrm{D}$ roughness parameters described in Table 2 were determined.

Additionally, a scale sensitive fractal analysis of the AFM and WLI data was performed using the software Sfrax (www.surfract.com). Area-scale analysis is based on the principle from fractal geometry that the area of a rough surface is not unique, but depends on the scale of measurement $[23,24]$. The software uses an iterative tiling algorithm in which the topography of the surface is modeled using triangular tiles to calculate the relative area as a function of the scale of observation. The area of a tile represents the scale, and the relative area is determined from the following formula: 


$$
A_{r}=\frac{N * A_{t}}{A_{p}}
$$

where $A_{r}$ is the relative area, $A_{t}$ is the area of a tile, $A_{p}$ is the projected area and $\mathrm{N}$ is the number of tiles.

An example of semi-log plot obtained by scale sensitive fractal analysis is shown Figure 10-a. This kind of plot can be split into two parts:

- The left part, in which the curve appears to be steep and linear. The slope of the curve is an indication of the complexity, intricacy or roughness of the surface [23]. The fractal dimension (D) can be estimated by adding two to the absolute value of the slope.

- The right part, in which the relative area approaches one.

The scale (i.e. the area of the tiles) corresponding to the limit between the two parts of the graph is called the smooth-rough crossover (SRC). For scales smaller than the SRC, the surface is considered as "rough", whereas for scales higher than SRC, the surface is considered as "smooth" [24].

\section{Results}

\subsection{Preliminary study: determination of adequate etching conditions}

The mass loss of the samples was strongly dependent on the etching time and there seems to be an exponential relationship between the mass loss and the HF concentration (Figure 1). For the HF 5\% solution, the mass loss was almost insignificant during the first hours but increased substantially for the longest etching time (24 h).

The values of the roughness parameters determined from AFM and WLI measurements differed (Figure 1), which could be expected because of the distinct 
resolutions and areas of measurement of both techniques, but in general evidenced the same tendencies:

- For HF 5\%, $S_{a}, S_{d r}$ and $S_{z}$ increased very slowly in a first phase which we will call the "initiation phase", and then more rapidly in a second phase which we will call the "effective etching phase". This evolution correlates with the mass loss measurements.

- For HF $20 \%$, there was a short "initiation phase", followed by an "effective etching phase". For long etching times, the increase rate of $S_{a}$ and $S_{d r}$ diminished.

- For HF $40 \%$, the "initiation phase" was probably too short to be observed. In a first stage, $S_{a}, S_{d r}$ and $S_{z}$ increased rapidly with etching time, then $S_{a}$ increased more slowly, $S_{d r}$ seemed to decrease and $S_{z}$ decreased or increased slightly depending on the measurement device. The maximal value of $S_{\mathrm{dr}}$ was reached for one hour of etching with AFM and for two hours with WLI. The ratios $\mathrm{S}_{\mathrm{z}} / \mathrm{S}_{\mathrm{a}}$ and $\mathrm{S}_{\mathrm{Z}} / \mathrm{S}_{\mathrm{dr}}$ were low as compared to other concentrations.

\subsection{Analysis of the etching solution}

The identification of the species present in the solution was performed by comparing the different series of peaks from both positive and negative mass spectra to theoretical simulation. The analysis evidenced the presence of zirconium fluoride, zirconium oxide and zirconium hydroxide complexes (Table 3). The presence of compounds containing Yttrium was not detected. It has to be taken into account that the solution which was subjected to ESI-FTMS was obtained by redissolution of the dry residue of the etching solution, therefore only non-volatile species were present and some structural changes may have occurred during the process. For two series of peaks of the positive-ion 
spectrum, the search for corresponding chemical compounds resulted in non-matching results however the isotopic profiles were characteristic of the presence in the compound of respectively one or two Zirconium ions.
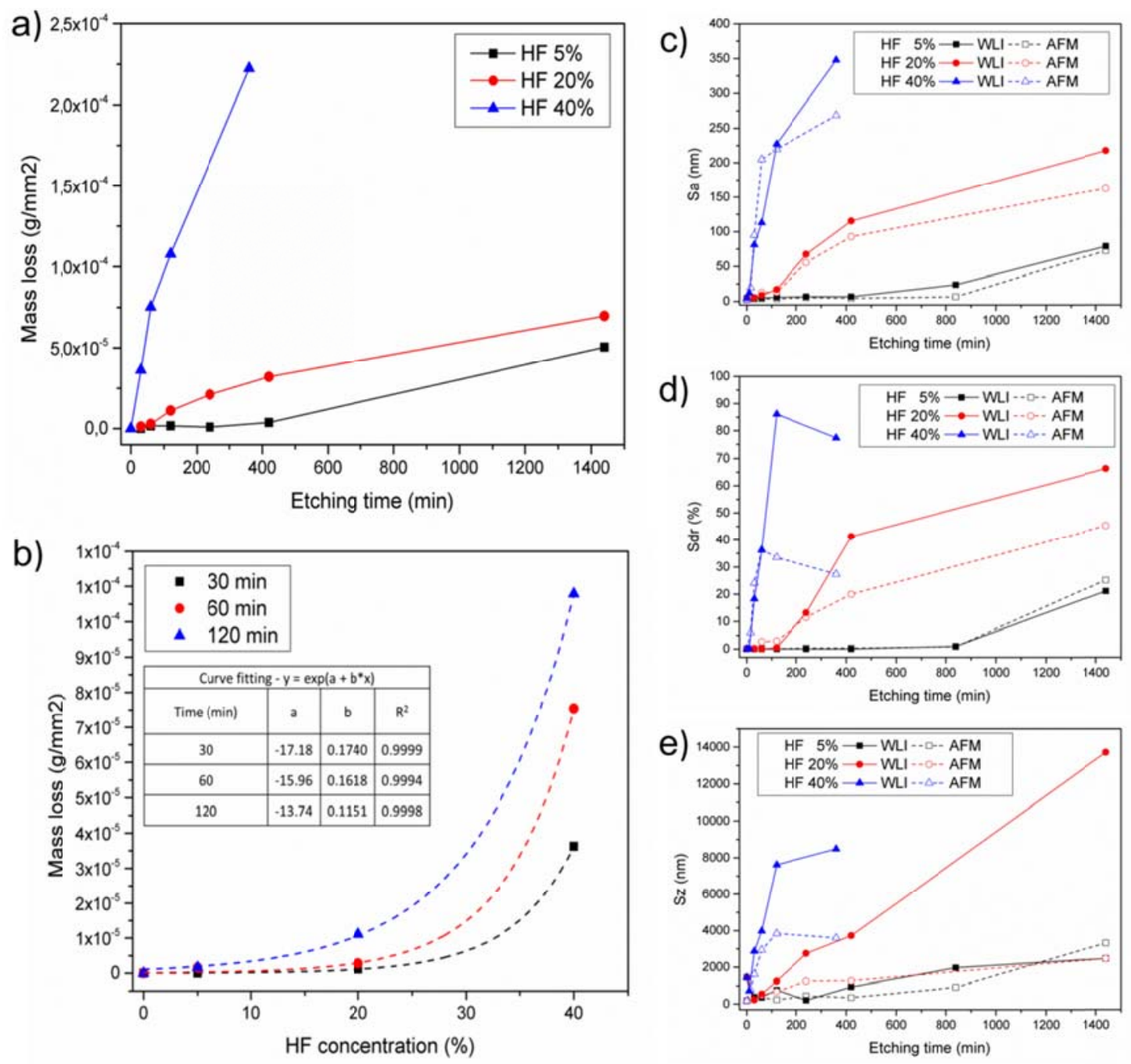

Figure 1. Left: mass loss per initial sample external area as a function of a) etching time for different HF concentrations, b) HF concentration for different etching times. Right: c) Sa, d) Sdr and e) Sz parameters determined from AFM and WLI data as a function of etching time for different HF concentrations. For all graphs each data point corresponds to a distinct specimen. 
Table 3. ESI-FTMS peaks identification.

\begin{tabular}{|c|c|c|c|}
\hline Polarization & $\begin{array}{l}\text { Region of the } \\
\text { spectrum }\end{array}$ & Compatible ions & Comments \\
\hline+ & $122 \mathrm{mDa}-132 \mathrm{mDa}$ & {$[\mathrm{ZrO}(\mathrm{OH})]^{+}$} & $\begin{array}{l}\text { Relative intensities } \\
\text { slightly diverged from } \\
\text { theory. }\end{array}$ \\
\hline+ & $140 \mathrm{mDa}-148 \mathrm{mDa}$ & {$\left[\mathrm{Zr}(\mathrm{OH})_{3}\right]^{+}$} & \\
\hline+ & $182 \mathrm{mDa}-198 \mathrm{mDa}$ & $\frac{\left[\mathrm{ZrO} .2 \mathrm{H}_{2} \mathrm{O} \cdot \mathrm{HCOOH}\right]^{+}}{\left[\mathrm{ZrF}_{3} \cdot \mathrm{CH}_{3} \mathrm{CN}\right]^{+}}$ & $\begin{array}{l}\mathrm{HCOOH} \text { and } \mathrm{CH}_{3} \mathrm{CN} \\
\text { come from the } \\
\text { redissolution and/or the } \\
\text { mobile phase. }\end{array}$ \\
\hline+ & $228 \mathrm{mDa}-236 \mathrm{mDa}$ & $\underset{\left.{ }_{3} \mathrm{CN}\right]^{+}}{\left[\mathrm{ZrOH} .2 \mathrm{H}_{2} \mathrm{O} . \mathrm{HCOOH} . \mathrm{CH}\right.}$ & $\begin{array}{l}\mathrm{HCOOH} \text { and } \mathrm{CH}_{3} \mathrm{CN} \\
\text { come from the } \\
\text { redissolution and/or } \\
\text { mobile phase. }\end{array}$ \\
\hline+ & $359 \mathrm{mDa}-366 \mathrm{mDa}$ & Not identified & $\begin{array}{l}\text { Characteristic isotopic } \\
\text { profile of the presence of } \\
1 \text { atom of } \mathrm{Zr} \text {. }\end{array}$ \\
\hline+ & $392 \mathrm{mDa}-412 \mathrm{mDa}$ & Not identified & $\begin{array}{l}\text { Characteristic isotopic } \\
\text { profile of the presence of } \\
2 \text { atoms of } Z \text { r. }\end{array}$ \\
\hline- & $180 \mathrm{mDa}-195 \mathrm{mDa}$ & {$\left[\mathrm{ZrF}_{5}\right]^{-}$} & \\
\hline- & $205 \mathrm{mDa}-225 \mathrm{mDa}$ & {$\left[\mathrm{ZrF}_{4} \cdot \mathrm{HCOO}^{-}\right.$} & $\begin{array}{l}\mathrm{HCOO}^{-} \text {comes from the } \\
\text { mobile phase. }\end{array}$ \\
\hline- & $350 \mathrm{mDa}-365 \mathrm{mDa}$ & {$\left[\mathrm{Zr}_{2} \mathrm{~F}_{9}\right]^{-}$} & \\
\hline
\end{tabular}

\subsection{Analysis of the etching products}

\subsubsection{Particles in suspension in the cleaning water}

The observation by TEM of the particles present in suspension in the DI water used for ultrasonic cleaning of samples etched two hours in HF $40 \%$ showed the presence of octahedral particles (octahedrons) and needle-like particles (needles) (Figure 2).

The selected area electron diffraction (SAED) pattern of an octahedron showed a crystalline structure, which is consistent with their regular shape. The SAED of a needle revealed a textured polycrystalline structure. In both patterns, low intensity quasiamorphous rings were observed. 
EDS analysis of the octahedrons showed that they are composed of Yttrium and Fluorine (Figure 2-e). The EDS analysis of the needles substantiated that they are composed of Yttrium, Zirconium and Fluorine (Figure 2-f).

\subsection{2. "As etched" surface}

SEM observations of the "as etched" surface showed the presence of octahedrons (Figure 3). The average size of the octahedrons increased with the etching time. Besides, an additional "adhered layer" appeared between $40 \mathrm{~min}$ and $60 \mathrm{~min}$. Some features similar to the needles described previously could be observed in the layer however it was not possible to acquire images at sufficiently high magnification to confirm it because of charge effects. EDS analysis of the octahedrons and the "adhered layer" revealed the presence of Zirconium, Yttrium and Fluorine (Figure 4-a and Figure 4-b). However, the proportion of Zirconium in the octahedrons was low, and given the previous EDS analysis of the particles present in the cleaning water, it is probable that the signal was originated from the material below.

The XPS quantitative analysis evidenced substantial increases in Yttrium and Fluorine together with substantial decreases in Zirconium and Oxygen concentrations as compared to the non-etched sample (Figure 4-d). Most of the peaks of the highresolution spectra could be identified (Table 4). In particular, the presence of $\mathrm{ZrF}_{4}$ and $\mathrm{YF}_{3}$ chemical bonds was detected. 

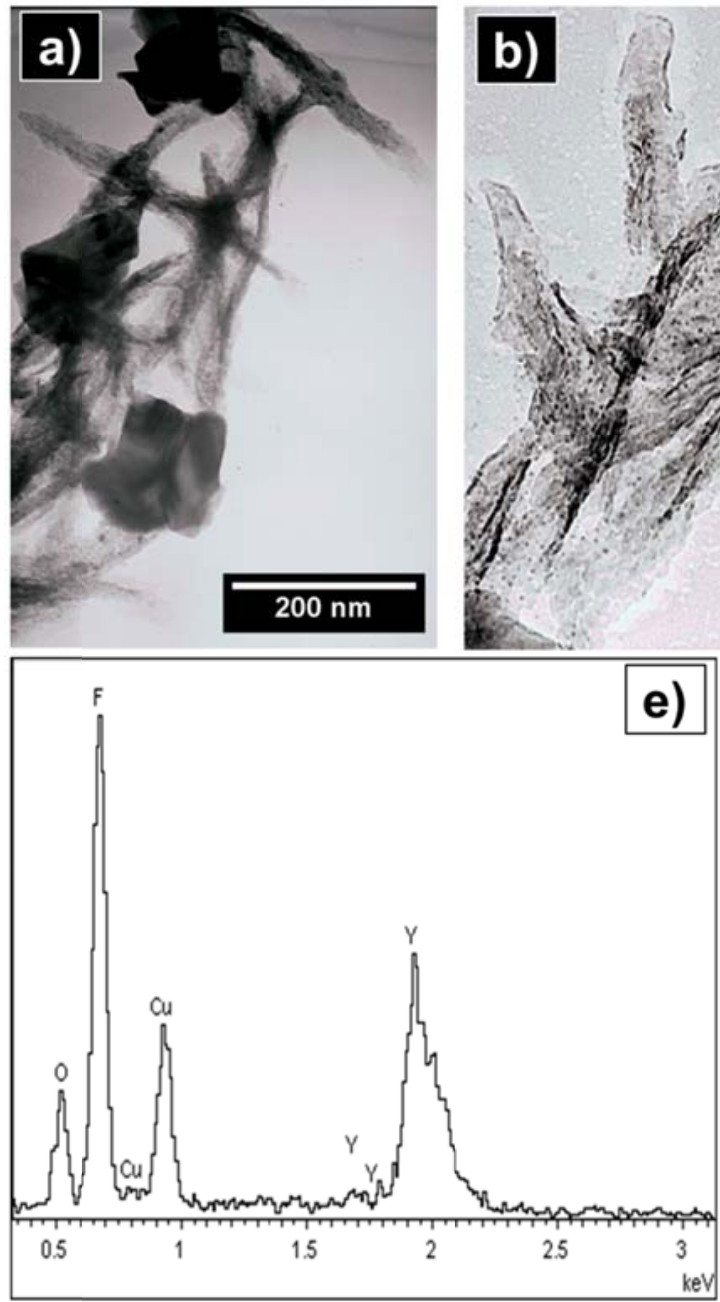
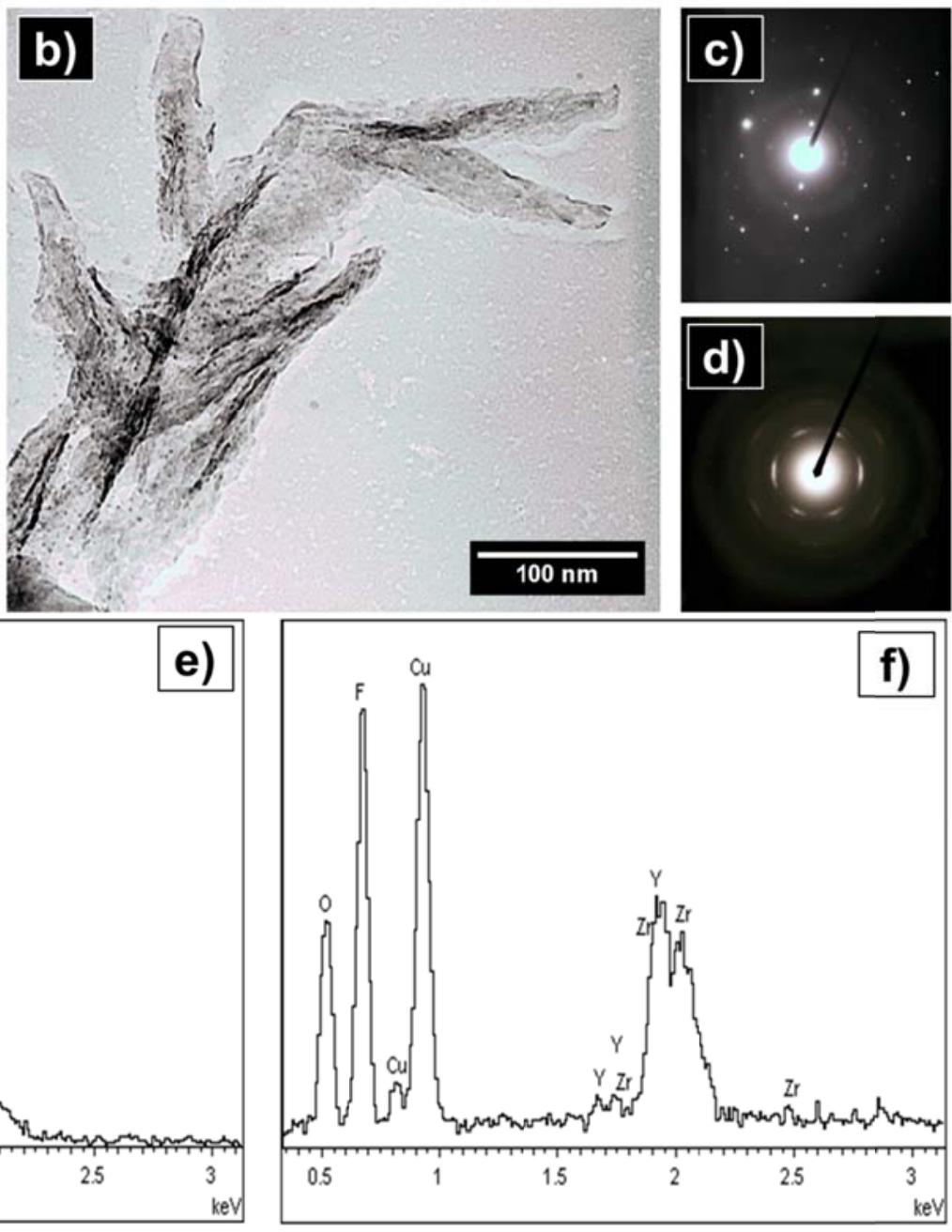

Figure 2. Observation by TEM (top) and EDS (bottom) of the particles present in the DI water used for ultrasonic cleaning of a sample etched two hours in HF $40 \%$ : a) agglomerate of octahedrons and needles, b) a needle at high magnification, c) SAED pattern of an octahedron, evidencing a crystalline structure, d) SAED pattern of a needle, evidencing a textured polycrystalline structure, e) EDS spectrum of an octahedron, f) EDS spectrum of a needle. In e) and f), $\mathrm{Cu}$ and $\mathrm{O}$ signals come from the substrate. 

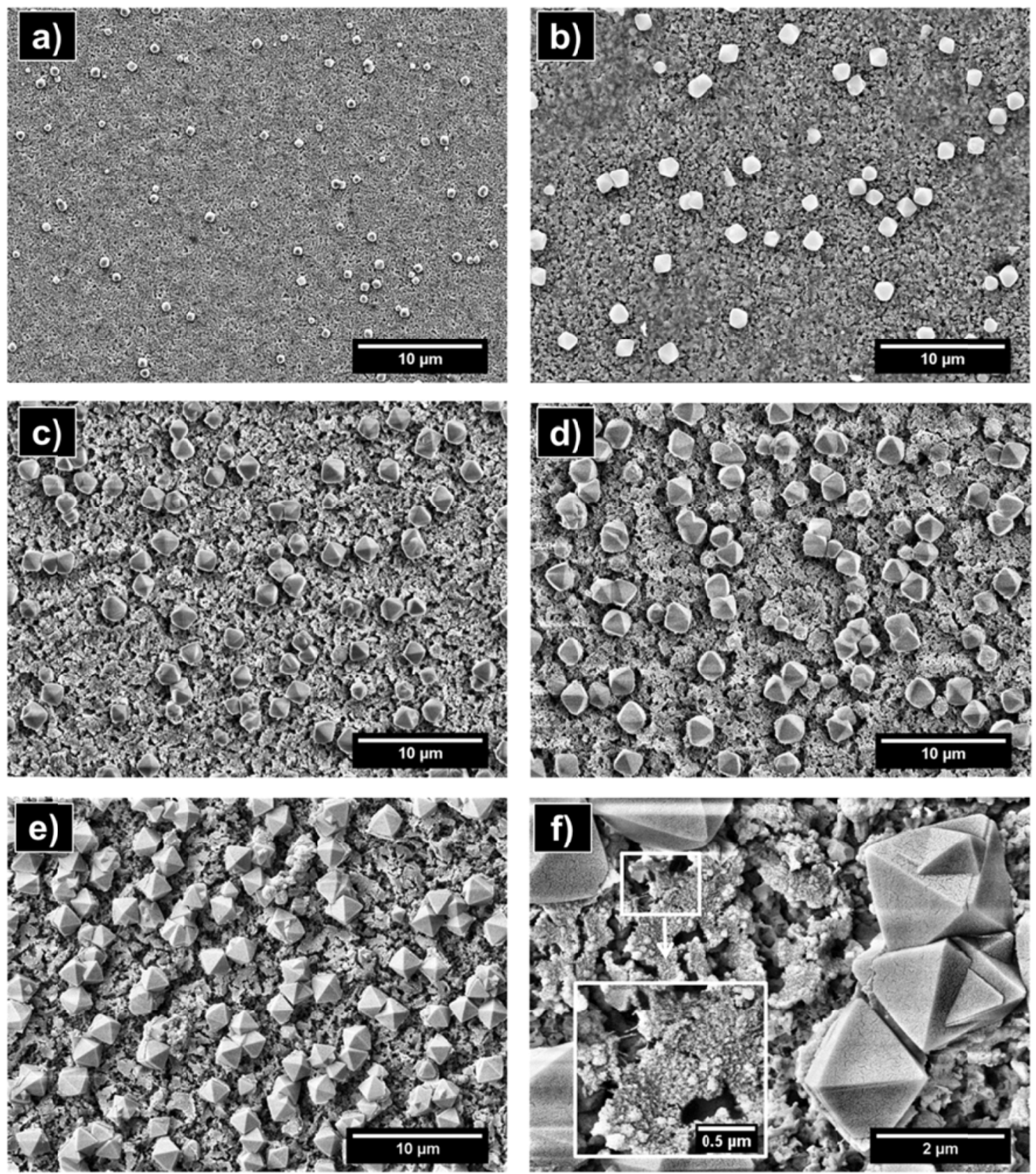

Figure 3. SEM observations of the surface in the "as etched" state (no ultrasonic cleaning) after etching in HF 40\% for: a) $20 \mathrm{~min}$, b) $40 \mathrm{~min}$, c) $60 \mathrm{~min}$, d) $90 \mathrm{~min}$, e) 120 min, f) 120 min (high magnification). The inset in f) shows the "adhered layer" at high magnification and possibly the same needles as observed Figure 2. 

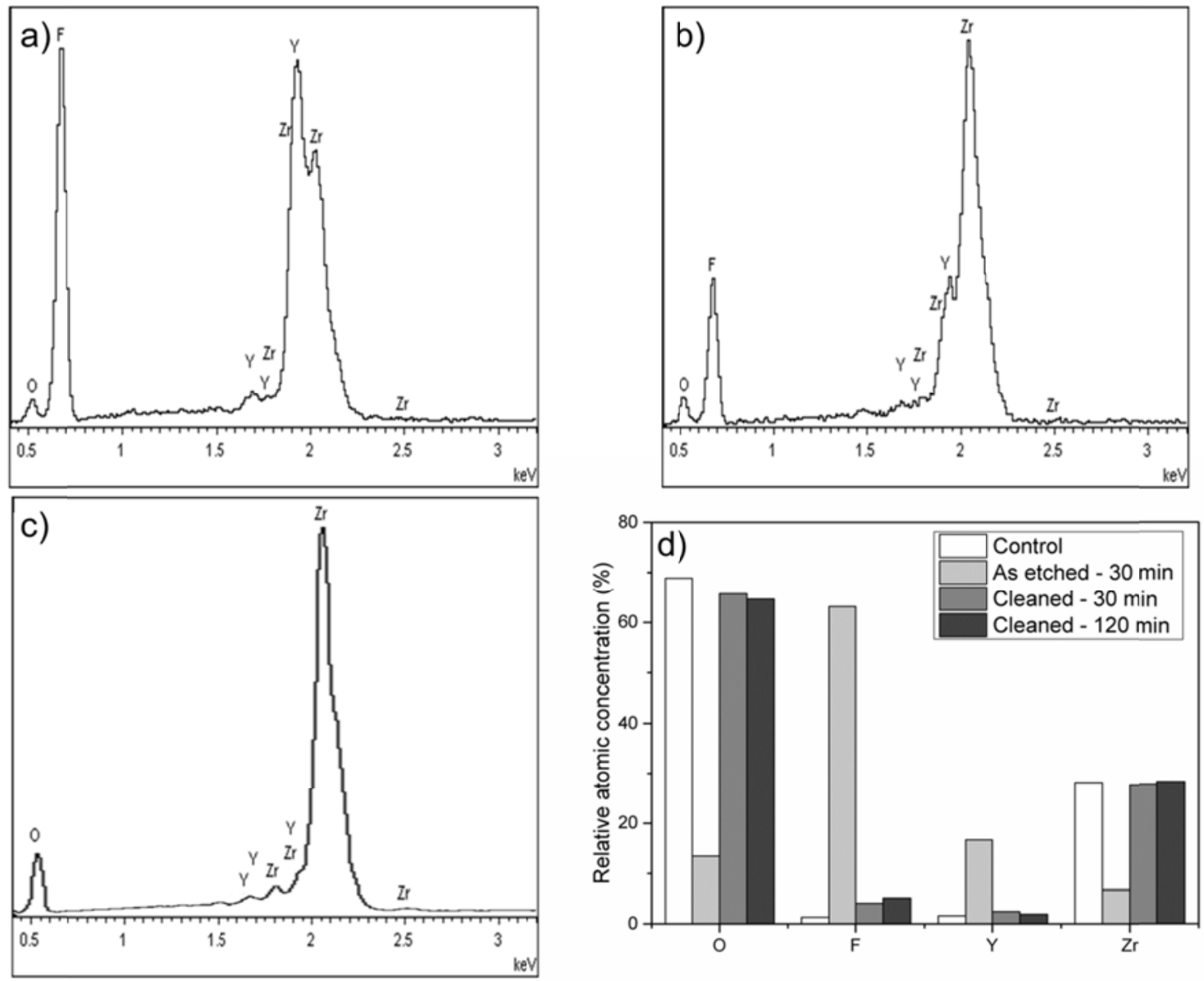

Figure 4. Quantitative elemental analysis performed on the "as etched" ( $a, b, d)$ and on the ultrasonically cleaned (c, d) surface. a) EDS spectrum of an octahedron, b) EDS spectrum of the "adhered layer", c) EDS spectrum of the cleaned surface, d) XPS quantitative analysis. 
Table 4. Identification of the peaks of the XPS high-resolution spectra of an "as etched" surface (spectra available in the supplementary information).

\begin{tabular}{|c|c|c|c|c|c|}
\hline Element & Orbital & $\begin{array}{c}\text { Binding } \\
\text { energy }(\mathrm{eV})\end{array}$ & $\begin{array}{c}\text { Closest value found in } \\
\text { the literature }(\mathrm{eV})\end{array}$ & $\begin{array}{c}\text { Identified chemical } \\
\text { environment }\end{array}$ & Reference \\
\hline \multirow{2}{*}{$F$} & \multirow{2}{*}{$1 \mathrm{~s}$} & 683.2 & - & - & - \\
\hline & & 684.9 & 685.1 & $\mathrm{ZrF}_{4} ; \mathrm{YF}_{3}$ & {$[25] ;[26]$} \\
\hline \multirow{3}{*}{$\mathrm{O}$} & \multirow{3}{*}{$1 \mathrm{~s}$} & 526.6 & - & - & - \\
\hline & & 528.8 & 528.8 & Pure $\mathrm{Y}_{2} \mathrm{O}_{3}$ (cubic) & [27] \\
\hline & & 531.4 & 531.3 & $\mathrm{ZrO}_{2}$ & {$[28]$} \\
\hline \multirow{2}{*}{ Y } & $3 \mathrm{~d} 3 / 2$ & 161.7 & - & $\mathrm{YF}_{3}$ & - \\
\hline & $3 \mathrm{~d} 5 / 2$ & 159.6 & 159.8 & $\mathrm{YF}_{3}$ & [26] \\
\hline \multirow{4}{*}{$\mathrm{Zr}$} & \multirow{2}{*}{$3 \mathrm{~d} 3 / 2$} & 183.8 & 184.0 & 3Y-TZP & {$[27]$} \\
\hline & & 187.6 & - & $\mathrm{ZrF}_{4}$ & - \\
\hline & \multirow{2}{*}{$3 \mathrm{~d} 5 / 2$} & 181.5 & 181.6 & 3Y-TZP & [27] \\
\hline & & 185.3 & 185.3 & $\mathrm{ZrF}_{4}$ & [29] \\
\hline
\end{tabular}

\subsection{Surface characterization}

\subsubsection{Surface morphology}
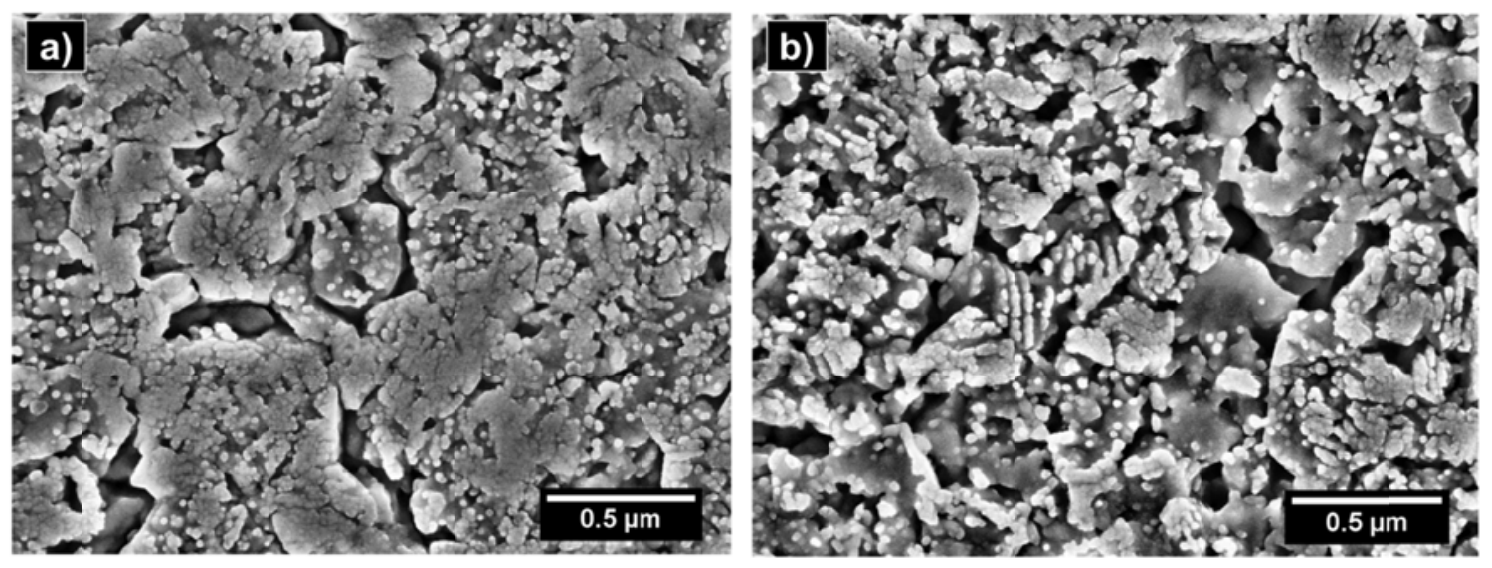

Figure 5. SEM observations of the surface for $5 \mathrm{~min}(\mathrm{a})$ and $10 \mathrm{~min}$ (b) of etching in HF 40\%, evidencing intergranular and intragranular etching.

After the cleaning procedure, SEM inspection of the samples did not evidence any remaining octahedrons or "adhered layer" on the surface, confirming the ultrasonic cleaning efficiency. Regarding the preferentiality of the etching, SEM observations showed that the attack was both intergranular and intragranular (grain size of the 
original material measured by the intercept method: $0.3 \mu \mathrm{m}$ ), being slightly faster at the grain boundaries (Figure 5) and demonstrated a substantial evolution of the morphology at different scales depending on etching time (Figure 6). Nevertheless, observations at high magnification showed no significant evolution of the granular texture. On the other hand, the presence of randomly dispersed pits was detected on the surface.

$30 \mathrm{~min}$
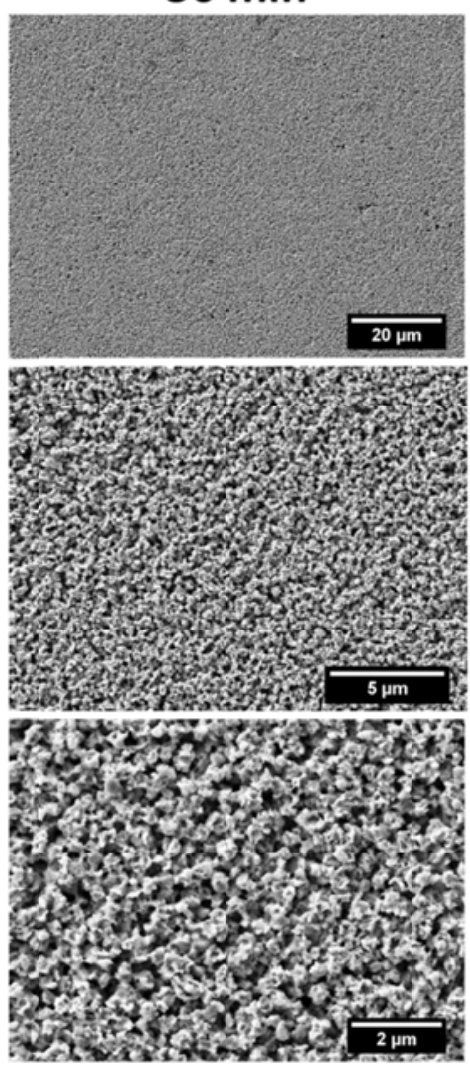

$1 \mathrm{~h}$
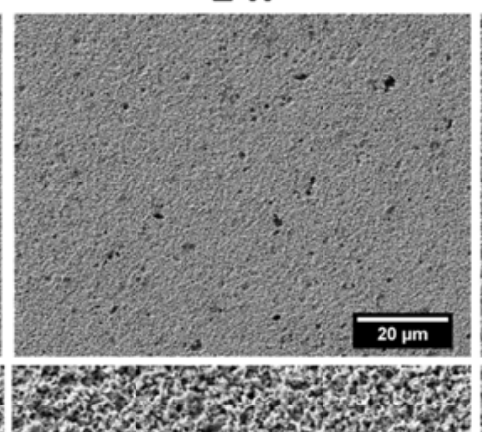
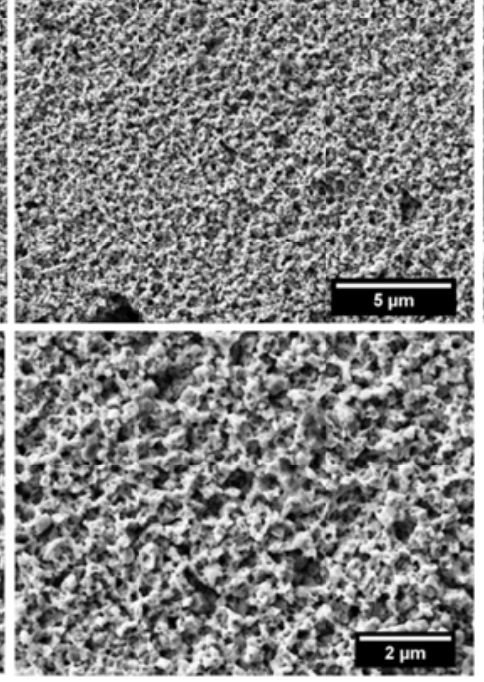

$2 \mathrm{~h}$
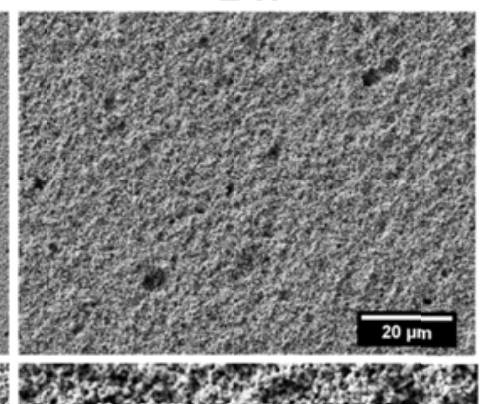
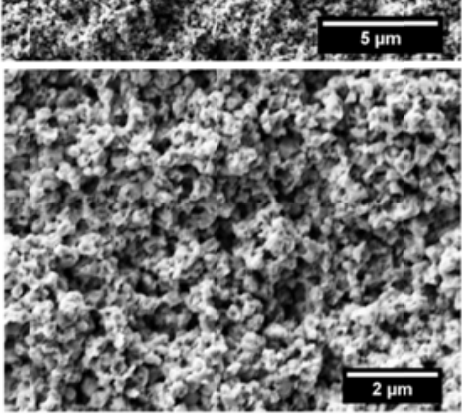

Figure 6. SEM observations of the surface at different magnifications and for different etching times in HF $40 \%$.

\subsubsection{Surface chemistry}

The results of XPS indicated a slight increase of the Fluorine content and a slight decrease of the Oxygen content in the first nanometers of the surface of etched samples as compared to the non-etched (control) sample (Figure 4-d). However the results of EDS showed that at the micrometric level the chemical composition of the surface was 
not substantially affected by etching, in particular the presence of Fluorine was not detected (Figure 4-c). As it will be discussed further, the analysis of the XPS highresolution spectra allowed identifying the chemical environment corresponding to most of the peaks (Table 5).

Table 5. Identification of the peaks of the XPS high-resolution spectra of an etched surface after ultrasonic cleaning (spectra available in the supplementary information).

\begin{tabular}{|c|c|c|c|c|c|}
\hline Element & Orbital & $\begin{array}{c}\text { Binding } \\
\text { energy }(\mathrm{eV})\end{array}$ & $\begin{array}{l}\text { Closest value found } \\
\text { in the literature } \\
(\mathrm{eV})\end{array}$ & $\begin{array}{l}\text { Identified chemical } \\
\text { environment }\end{array}$ & Reference \\
\hline $\mathrm{F}$ & $1 \mathrm{~s}$ & 683.1 & - & - & - \\
\hline \multirow{3}{*}{$\mathrm{O}$} & \multirow{3}{*}{$1 \mathrm{~s}$} & 527.9 & - & - & - \\
\hline & & 529.3 & 529.3 & 3Y-TZP & [27] \\
\hline & & 531.3 & 531.0 & $\mathrm{YOOH}$ & {$[27,30]$} \\
\hline \multirow{4}{*}{ Y } & \multirow{2}{*}{$3 \mathrm{~d} 3 / 2$} & 158.4 & 158.6 & 3Y-TZP & {$[27]$} \\
\hline & & 160.1 & - & $\mathrm{YOOH}$ & - \\
\hline & \multirow{2}{*}{$3 \mathrm{~d} 5 / 2$} & 156.3 & 156.5 & 3Y-TZP & [27] \\
\hline & & 158.1 & 158.5 & $\mathrm{YOOH}$ & [30] \\
\hline \multirow{2}{*}{$\mathrm{Zr}$} & $3 \mathrm{~d} 3 / 2$ & 184.1 & 184.0 & 3Y-TZP & [27] \\
\hline & $3 \mathrm{~d} 5 / 2$ & 181.7 & 181.6 & 3Y-TZP & [27] \\
\hline
\end{tabular}

\subsubsection{Surface topography}

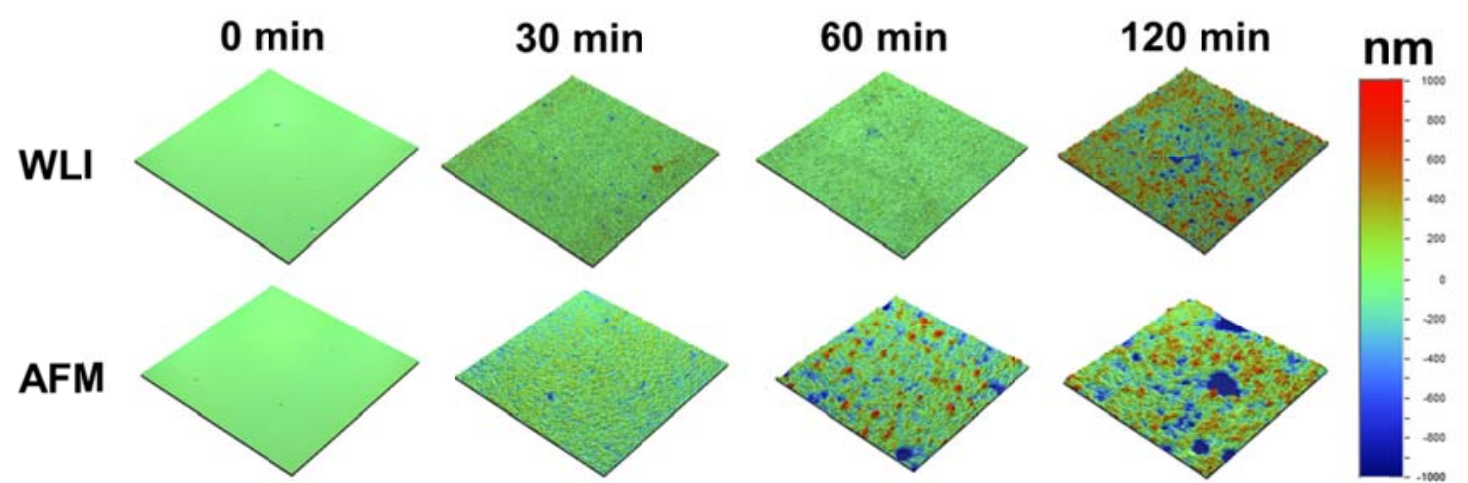

Figure 7. WLI $(150 \mu \mathrm{m} \times 150 \mu \mathrm{m})$ and AFM $(50 \mu \mathrm{m} \times 50 \mu \mathrm{m})$ topographical images for different etching times in HF 40\%. 
AFM and WLI images revealed a substantial evolution of the topography depending on the etching duration (Figure 7). The apparition of high peaks and deep valleys was more pronounced for long etching times.

\subsubsection{Roughness analysis}
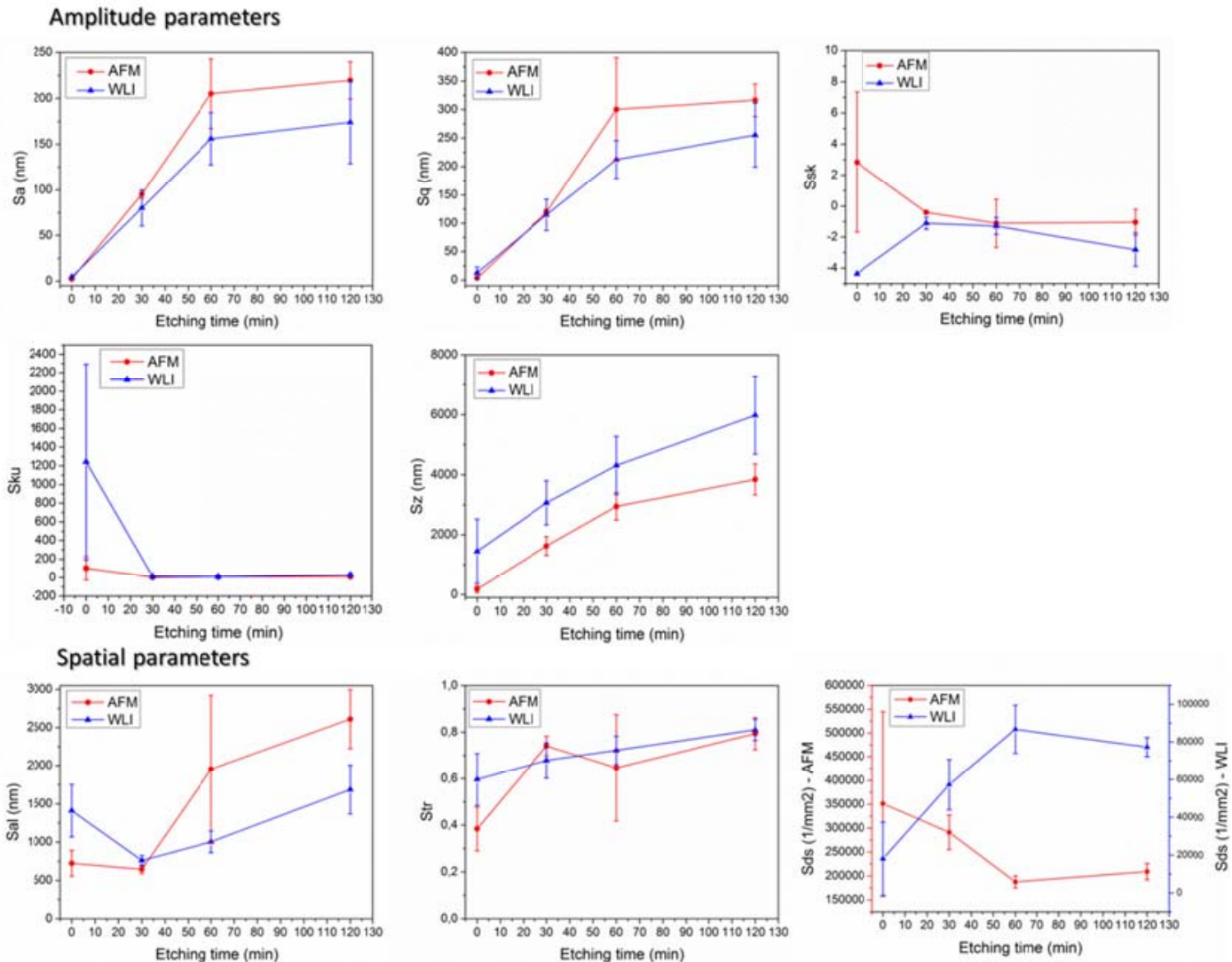

Figure 8. Evolution of amplitude and spatial roughness parameters over etching time in HF $40 \%$ determined from AFM and WLI measurements. Error bars represent the standard deviation.

\section{- Amplitude parameters (Figure 8)}

For both AFM and WLI measurements, the surface average roughness $\left(\mathrm{S}_{\mathrm{a}}\right)$ and RMS roughness $\left(\mathrm{S}_{\mathrm{q}}\right)$ increased substantially from zero to one hour and then slightly between one hour and two hours. The ten point peak-peak height $\left(\mathrm{S}_{\mathrm{z}}\right)$ increase was substantial even after one hour. The skewness $\left(\mathrm{S}_{\mathrm{sk}}\right)$ was negative after etching, 
indicating that valleys were predominant on the surface and the kurtosis (Sku) was superior to three, indicating a narrow height distribution and steep side-walls.

- Spatial parameters (Figure 8)

For both AFM and WLI measurements, the texture aspect ratio $\left(\mathrm{S}_{\mathrm{tr}}\right)$ approached the value of one when increasing the etching duration, which evidenced that the process leads to an isotropic surface. The fastest decay length $\left(\mathrm{S}_{\mathrm{al}}\right)$ first decreased from zero to thirty minutes but then increased from thirty minutes to two hours. The density of summits $\left(\mathrm{S}_{\mathrm{ds}}\right)$ evidenced a different behavior at small and large scale. At small scale (AFM measurements), the $S_{d s}$ decreased with etching time to reach a minimum at $t=60$ min, meanwhile it increased at large scale (WLI measurements) to reach a maximum at the same time point.

- $\quad$ Hybrid parameters (Figure 9)

For both AFM and WLI measurements, the RMS gradient $\left(S_{\mathrm{dq}}\right)$, the mean summit curvature $\left(\mathrm{S}_{\mathrm{sc}}\right)$ and the developed interfacial area ratio $\left(\mathrm{S}_{\mathrm{dr}}\right)$ reached a maximum after one hour of etching and then remained almost constant.

- Functional parameters (Figure 9)

For both AFM and WLI measurements, the bearing index $\left(\mathrm{S}_{\mathrm{bi}}\right)$ first decreased from zero to thirty minutes and then increased slightly from thirty minutes to two hours, whereas the opposite happened with the core fluid retention index $\left(\mathrm{S}_{\mathrm{ci}}\right)$. The valley fluid retention index $\left(\mathrm{S}_{\mathrm{vi}}\right)$ had a slightly different evolution depending on the scale: for WLI measurements it increased until thirty minutes, and then remained constant, whereas for AFM measurements the maximum value was reached only after two hours. 
For both AFM and WLI measurements, the surface material volume $\left(\mathrm{S}_{\mathrm{m}}\right)$ and the surface core void volume $\left(\mathrm{S}_{\mathrm{c}}\right)$ increased significantly until one hour and then remained almost constant. By contrast, the surface valley void volume $\left(\mathrm{S}_{\mathrm{v}}\right)$ kept increasing after one hour of etching, especially considering WLI measurements.
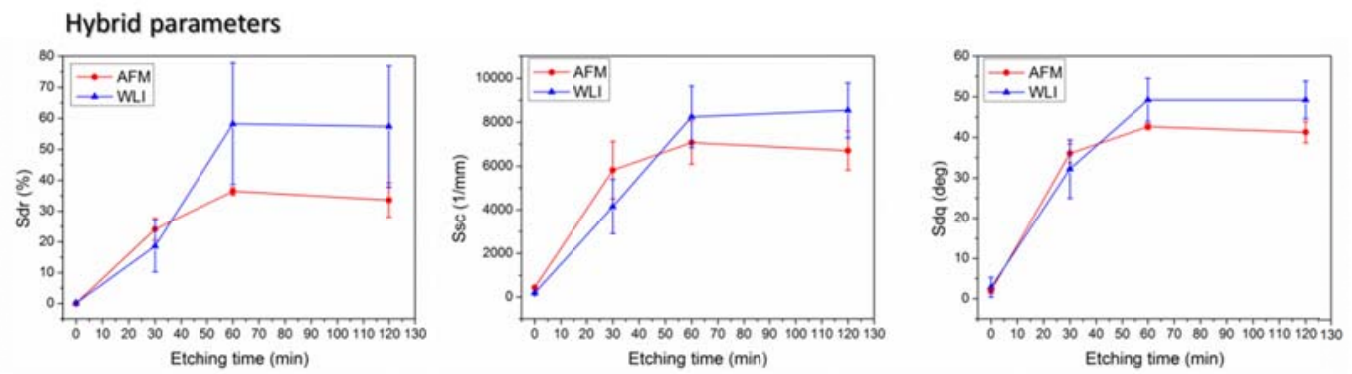

Functional parameters
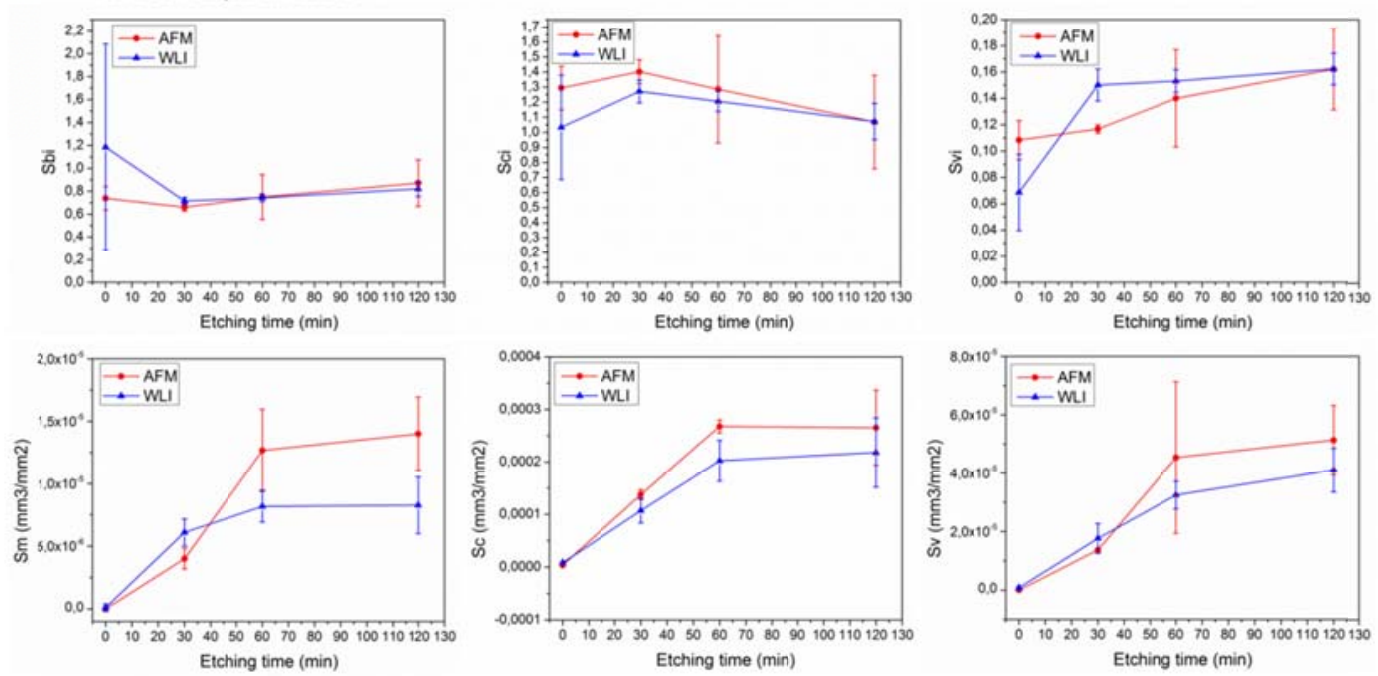

Figure 9. Evolution of hybrid and functional roughness parameters over etching time in HF $40 \%$ determined from AFM and WLI measurements. Error bars represent the standard deviation.

\subsubsection{Fractal analysis}

Scale-sensitive fractal analysis of both AFM and WLI data showed that in the first hour of etching the fractal dimension D increased rapidly over time, and then did not evolve substantially (Figure 10-e). Regarding the Smooth-Rough Crossover, results diverged depending on the technique: the analysis of the AFM data showed that the 

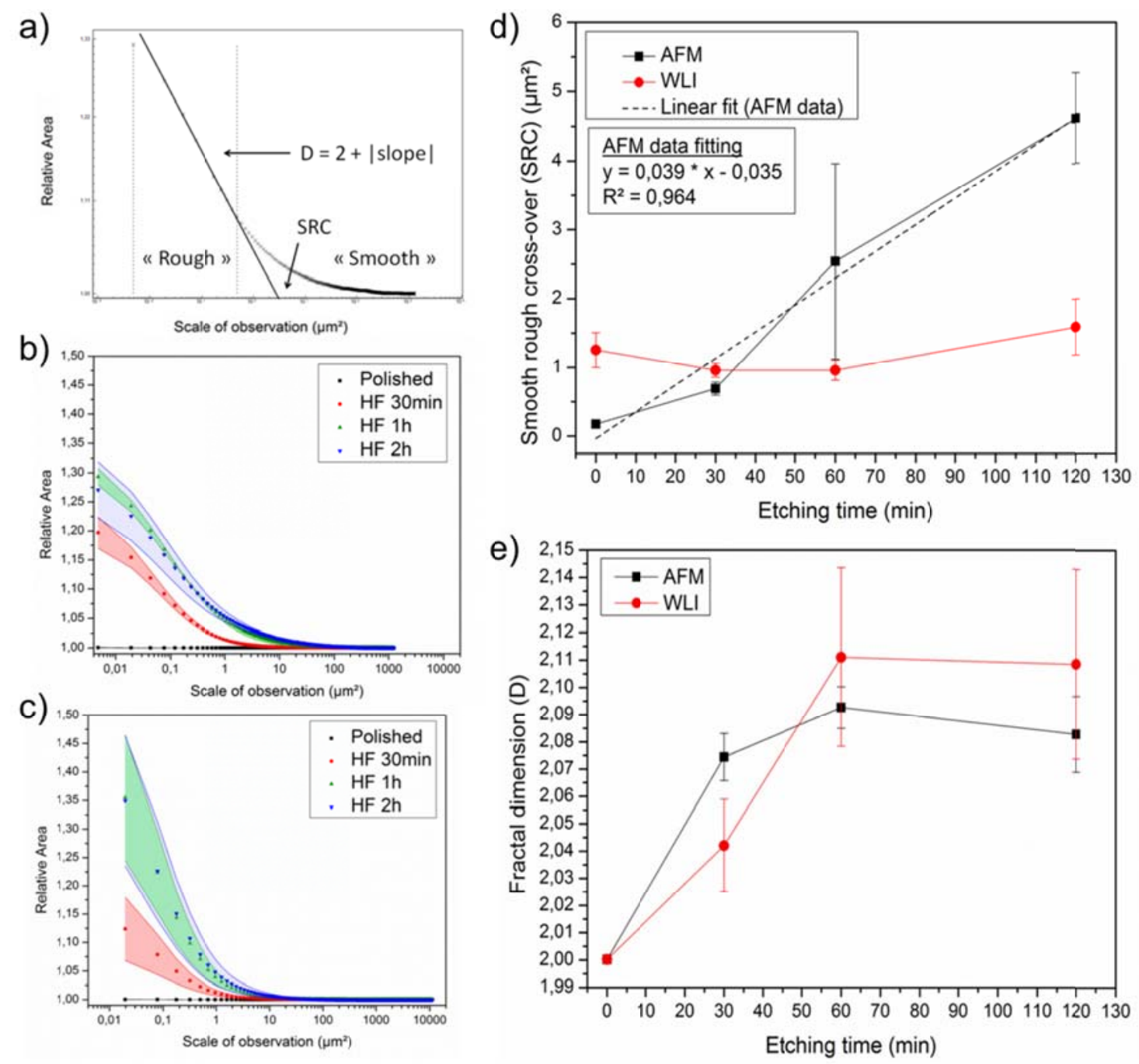

Figure 10. a) Example of scale-sensitive fractal analysis, showing how SRC and fractal dimension are obtained, b) relative area as a function of the scale of observation for different etching times in HF $40 \%$ calculated from AFM data, c) the same with WLI data, d) Smooth-Rough Crossover as a function of etching time determined from b) and c), e) fractal dimension as a function of etching time determined from b) and c). The vertical distance between solid lines in b) and c) and the error bars in d) and e) represent the standard deviation at each point.

SRC tended to increase proportionally to the etching time whereas the analysis of the WLI data did not evidence any substantial evolution (Figure 10-d). This discrepancy was probably due to the distinct lateral resolution and area of measurement associated to 
each technique, which, besides, implies a different range of scales for which the relative area can be computed by the tiling algorithm.

\section{Discussion}

\subsection{Preliminary study: determination of adequate etching conditions}

The exponential relationship between the mass loss and the HF concentration may indicate a phenomenon of auto-catalysis as it has been observed for instance during the HF etching of silicon oxide [31,32]. On one hand, the reaction products could increase the etch rate. On the other hand, the $\mathrm{S}_{\mathrm{dr}}$ increase over time implies an increase of the area available for reacting and thus a faster etching.

Since a high value of $S_{a}$ is crucial for osseointegration [8], HF $40 \%$ seems to be the most suitable etching solution because it leads to the most substantial increase of this parameter in the minimum amount of time. Moreover HF $40 \%$ likely leads to a more homogeneous etching of the surface: the value of the relation $S_{z} / S_{a}$ is low compared to other concentrations, which indicates probably less exceptional events such as very deep valleys (for instance pits) / high peaks. On the other hand, $\mathrm{S}_{\mathrm{dr}}$, which is another important parameter for osseointegration [8] decreased after two hours of etching in HF $40 \%$ whereas the mass loss kept increasing, potentially inducing more damage to the material. It appears thus that within the limits of this study a concentration of $40 \%$ and an etching time below two hours are the most appropriate conditions for the etching of zirconia dental implants.

\subsection{Analysis of the etching solution}

The results of ESI-FTMS highlighted that the etching of 3Y-TZP with HF leads to the formation of soluble zirconium complexes. Two compounds could not be identified however their isotopic profiles evidenced that they contained Zirconium. Consequently 
the presence of compounds containing Yttrium was unlikely although it cannot be discarded. Literature regarding the ESI-FTMS of Zirconium complexes is scarce, nevertheless the existence of hydroxides such as $\left[\mathrm{Zr}(\mathrm{OH})_{3}\right]+$ and of fluorides such as $\left[\mathrm{ZrF}_{5}\right]-$ and $\left[\mathrm{Zr}_{2} \mathrm{~F}_{9}\right]^{-}$is in good agreement with other studies [33-35]. Doubly charged species $\left[\mathrm{ZrF}_{6}\right]^{2-}$ were not observed, but solid salts such as $\mathrm{K}_{2} \mathrm{ZrF}_{6}$ or $\left(\mathrm{NH}_{4}\right)_{2} \mathrm{ZrF}_{6}$, and hexafluorozirconic acid $\left(\mathrm{H}_{2} \mathrm{ZrF}_{6}\right)$ are known to be stable. Therefore, taking into account that structural changes may have occurred during the drying/redissolution process, their presence in the original etching solution should not be excluded.

\subsection{Analysis of the etching products}

To the best of the knowledge of the authors, this is the first time that the presence of adhered reaction products on the surface of zirconia is reported during HF etching. For short etching times, only octahedrons were present. As evidenced by the SAED and the EDS analysis they are crystalline and composed of Yttrium and Fluorine. Besides, XPS showed the presence of $\mathrm{YF}_{3}$ bonds at the surface of "as etched" zirconia, which suggest that the octahedrons could be $\mathrm{YF}_{3}$ crystals. This hypothesis tends to be confirmed by their morphology which is consistent with what can be found in the literature regarding this kind of crystals [36].

After an etching time of about one hour, the "adhered layer" appears. EDS showed that it was composed of Zirconium, Yttrium and Fluorine, which is similar to the needles found in the cleaning water. Besides, some needle-like features were observed by SEM on the "as etched" surface. Therefore the adhered layer could be formed at least partially by an agglomeration of needles. The delayed apparition of the layer could be explained by the saturation of the solution with Zirconium fluorides. 
Finally, it should be highlighted that the effect of these reaction products on the bonding between implant and bone and on the patient health is unknown. This underlines the importance of the cleaning step in the fabrication of an HF etched implant. The procedure proposed in this work was very efficient as none of the reaction products described above was observed on the surface after sonication.

\subsection{Etching mechanism}

Literature regarding the etching mechanism of zirconia is very scarce. It seems that there has been only one attempt to describe the dissolution of $\mathrm{ZrO}_{2}$ in $\mathrm{HF}$ [37], but the study, based on the Pourbaix speciation diagrams, was essentially theoretical. Besides, the case of 3Y-TZP is more complex because of the presence of Yttrium oxide.

Based on the experimental results presented above, an attempt to describe the etching mechanism of $3 \mathrm{Y}-\mathrm{TZP}$ in $\mathrm{HF} 40 \%$, summarizing previous observations, is presented here:

- HF dissolves zirconium oxide and yttrium oxide. Fluoride, oxide, and hydroxide complexes are formed. Etching is slightly preferential at the grain border, but also occurs inside the grains.

- Yttrium complexes have very low solubility. From the beginning of the etching process, Yttrium trifluoride $\left(\mathrm{YF}_{3}\right)$ octahedral crystals precipitate on the surface.

- Zirconium complexes are partially soluble. After a certain time, an "adhered layer" composed of Yttrium, Zirconium and Fluorine precipitates, probably because the saturation threshold for Zirconium fluoride complexes is reached. It may be formed at least partially by agglomerated textured polycrystalline needles. 


\subsection{Surface characterization}

\subsubsection{Surface chemistry}

The binding energies associated to the $\mathrm{Zr} 3 \mathrm{~d}$ peaks, to the $\mathrm{O} 1 \mathrm{~s}$ peak at $529.3 \mathrm{eV}$ and the $\mathrm{Y} 3 \mathrm{~d}_{5 / 2}$ peak at $156.5 \mathrm{eV}$ found during the analysis of the XPS high-resolution spectra were in very good agreement with values found by Majumdar et al. for 3Y-TZP [27]. Besides, Fluorine was not detected during the EDS analysis. These two observations tend to indicate that the effect of HF etching on the surface chemistry is limited. Nevertheless, XPS quantitative analysis evidenced a small increase of the Fluorine content due to etching which indicates a slight change of composition in the very near surface, which was not related to etching time. Additionally, the presence of an $\mathrm{O} 1 \mathrm{~s}$ peak at $531.3 \mathrm{eV}$ and of the pair of $\mathrm{Y} 3 \mathrm{~d}$ peaks at $158.1 \mathrm{eV}$ and $160.1 \mathrm{eV}$ was compatible with the existence of yttrium hydroxide groups $[27,30]$. Contrary to what was observed for the "as etched" surface, the presence of $\mathrm{YF}_{3}$ and $\mathrm{ZrF}_{4}$ bonds was not detected. This confirms that the ultrasonic cleaning procedure is efficient and that the products precipitated during the reaction are not strongly adhered to the surface.

\subsubsection{Evolution of the surface topography over etching time}

The roughness parameters analysis showed that a transition takes place around one hour of etching:

- The increase rate of amplitude parameters such as $S_{a}$ and $S_{q}$ was high until one hour, and then became much lower. Nevertheless, the ten point peak-peak height $\mathrm{S}_{\mathrm{z}}$ kept increasing substantially even after one hour. The same tendency was observed when comparing functional parameters $S_{m}$ and $S_{c}$ to $S_{v}$. This indicates that although the average roughness, the surface material volume and the surface core void volume do not increase substantially after one hour, localized events such as etching pits likely become bigger. This was confirmed by topographical 
images (Figure 7) and is not desirable from the mechanical point of view since those localized events could act as defects originating fracture [18]. On the other hand, it has to be noticed that for the functional indexes $S_{b i}, S_{c i}$ and $S_{v i}$ the transition seems to happen around thirty minutes.

- The density of summits $S_{\mathrm{ds}}$ reached a maximum at large scale (WLI measurements) and a minimum at small scale (AFM measurements) for one hour of etching. This means that for longer etching times the number of large peaks tend to increase whereas the small peaks tend to be eroded.

- A maximum was reached around one hour for hybrid parameters $S_{d r}, S_{s c}$ and $S_{d q}$. This indicates that the specific surface, the summit curvature and the mean surface slope do not increase anymore beyond this time.

The scale sensitive fractal analysis confirmed that a transition takes place around one hour of etching: the fractal dimension first increased rapidly and then reached a plateau (Figure 10). The interpretation of the evolution of the Smooth-Rough Crossover is not as straightforward given the differences observed depending on the measurement device. As commented previously, these differences are likely to be due to the distinct lateral resolution and area of measurement. However, the analysis of AFM data tended to show that one of the effects of increasing etching time is to increase the scale at which the surface can be considered as "rough", as evidenced by the proportionality between the SRC and the time. This is substantiated by the evolution of the morphology which starts at small scale and continues at large scale for long etching times (Figure 6).

The main outcome of all these observations is that HF etching makes easy to tailor a surface with the desired smooth-rough transition, fractal dimension and roughness parameters. This constitutes an interesting result given the high sensitivity of osteoblasts to roughness at different scales [7,9,38-41] and the strong influence of fractal 
dimension on osteoblastic adhesion and differentiation [10]. Regarding the roughness parameters, although the lack of standardization in the measurements makes comparison difficult with other studies, the values of $S_{a}, S_{d r}, S_{d s}$ and $S_{c i}$ which were obtained here fall within the range of the reported values for commercial dental implants with proved high success rate $[8,42-44]$. On the other hand, the limited evolution of $S_{a}, S_{d r}, S_{d s}$ and $\mathrm{S}_{\mathrm{ci}}$ after one hour of etching tends to indicate that inferior etching times are more appropriate for the treatment of dental implants. Unfortunately most of the studies in the literature omit the other roughness parameters and therefore their influence on the bone response is currently not well understood.

\section{Conclusion}

The present work shows that HF etching of zirconia is a complex phenomenon involving the dissolution of Zirconium and Yttrium oxides and the precipitation of fluoride crystals, which is reported for the first time. The formation of these precipitates on the surface highlights the importance of the cleaning step, since their effect on the bonding between implant and bone and on the patient health is unknown. At room temperature and within the limits of this study, a concentration of $40 \%$ leads to the fastest and most uniform etching, and appears therefore to be the most appropriate for the treatment of zirconia dental implants. On the other hand, monitoring the etching time allows producing surfaces with controlled roughness, smooth-rough transition and fractal dimension. The roughness analysis was exhaustive and evidenced that a transition was taking place around one hour of etching, after which the evolution of the roughness parameters known to be important for osseointegration was limited. Chemical changes at the surface were moderate and not time related. This work could constitute a sound basis for future biological studies aiming at determining the influence of the topography of zirconia on cell response and osseointegration. 


\section{Acknowledgement}

The authors would like to acknowledge the European Commission funding under the 7th Framework Programme (Marie Curie Initial Training Networks; grant number: 289958, Bioceramics for bone repair), the support of the Ministry of Economy and Competitiveness (MINECO) of Spain (project ref. MAT2011-23913) and the Government of Catalonia for the grant 2014SGR0137. The authors would also like to thank Dr. Alberto Adeva and Dr. Isidre Casals for their help with ESI-FTMS measurements, Dr. Trifon Trifonov for his help during SEM sessions, Dr. Montserrat Dominguez for her help with XPS analysis, Prof. Christopher Brown and Benjamin Childs from the Worcester Polytechnic Institute (WPI) for providing a free license for the Sfrax software and Bénédicte Londiche, Hugo Pavailler and Gleb Sapunenko for their work related to sample preparation and AFM measurements.

\section{Abbreviations}

AFM, Atomic Force Microscopy; DI water, Deionized water; EDS, Energy Dispersive Spectrometry; ESI-FTMS, Electrospray Ionization Fourier Transform Mass Spectrometry; HF, Hydrofluoric acid; SEM, Scanning Electron Microscopy; SRC, Smooth-Rough Crossover; TEM, Transmission Electron Microscopy; WLI, White Light Interferometry; XPS, X-Ray Photoelectron Spectroscopy; Y-TZP, Yttriastabilized tetragonal zirconia polycrystals; 3Y-TZP, 3 mol\% Y-TZP. 


\section{References}

[1] Chevalier J. What future for zirconia as a biomaterial? Biomaterials 2006;27:535-43. doi:10.1016/j.biomaterials.2005.07.034.

[2] Denry I, Kelly JR. State of the art of zirconia for dental applications. Dent Mater 2008;24:299-307. doi:10.1016/j.dental.2007.05.007.

[3] Andreiotelli M, Wenz HJ, Kohal R-J. Are ceramic implants a viable alternative to titanium implants? A systematic literature review. Clin Oral Implants Res 2009;20 Suppl 4:32-47. doi:10.1111/j.1600-0501.2009.01785.x.

[4] Kohal R-J, Knauf M, Larsson B, Sahlin H, Butz F. One-piece zirconia oral implants: one-year results from a prospective cohort study. 1. Single tooth replacement. J Clin Periodontol 2012;39:590-7. doi:10.1111/j.1600051X.2012.01876.x.

[5] Osman RB, Swain M V, Atieh M, Ma S, Duncan W. Ceramic implants (Y-TZP): are they a viable alternative to titanium implants for the support of overdentures? A randomized clinical trial. Clin Oral Implants Res 2014;25:1366-77. doi:10.1111/clr.12272.

[6] Anil S, Anand PS, Alghamdi H, Jansen JA. Dental Implant Surface Enhancement and Osseointegration. Implant Dent. - A Rapidly Evol. Pract., 2005, p. 83-108. doi: $10.5772 / 16475$.

[7] Zink C, Hall H, Brunette DM, Spencer ND. Orthogonal nanometer-micrometer roughness gradients probe morphological influences on cell behavior. Biomaterials 2012;33:8055-61. doi:10.1016/j.biomaterials.2012.07.037.

[8] Wennerberg A, Albrektsson T. On implant surfaces: a review of current knowledge and opinions. Int J Oral Maxillofac Implants 2009;25:63-74.

[9] Coelho PG, Jimbo R, Tovar N, Bonfante E a. Osseointegration: Hierarchical designing encompassing the macrometer, micrometer, and nanometer length scales. Dent Mater 2015;31:37-52. doi:10.1016/j.dental.2014.10.007.

[10] Anselme K, Bigerelle M, Noel B, Dufresne E, Judas D, Iost A, et al. Qualitative and quantitative study of human osteoblast adhesion on materials with various surface roughnesses. J Biomed Mater Res 2000;49:155-66.

[11] Casucci A, Mazzitelli C, Monticelli F, Toledano M, Osorio R, Osorio E, et al. Morphological analysis of three zirconium oxide ceramics: Effect of surface treatments. Dent Mater 2010;26:751-60. doi:10.1016/j.dental.2010.03.020.

[12] Gruber R, Hedbom E, D. Bosshardt D, Heuberger R, Buser D. Acid and alkali etching of grit blasted zirconia: Impact on adhesion and osteogenic differentiation of MG63 cells in vitro. Dent Mater J 2012;31:1097-102. doi:10.4012/dmj.2012107. 
[13] Gahlert M, Röhling S, Wieland M, Eichhorn S, Küchenhoff H, Kniha H. A comparison study of the osseointegration of zirconia and titanium dental implants. A biomechanical evaluation in the maxilla of pigs. Clin Implant Dent Relat Res 2010;12:297-305. doi:10.1111/j.1708-8208.2009.00168.x.

[14] Ito H, Sasaki H, Saito K, Honma S, Yajima Y, Yoshinari M. Response of osteoblast-like cells to zirconia with different surface topography. Dent Mater J 2013;32:122-9. doi:10.4012/dmj.2012-208.

[15] Bergemann C, Duske K, Nebe JB, Schöne A, Bulnheim U, Seitz H, et al. Microstructured zirconia surfaces modulate osteogenic marker genes in human primary osteoblasts. J Mater Sci Mater Med 2015. doi:10.1007/s10856-0145350-x.

[16] Cooper LF, Zhou Y, Takebe J, Guo J, Abron A, Holmén A, et al. Fluoride modification effects on osteoblast behavior and bone formation at $\mathrm{TiO} 2$ gritblasted c.p. titanium endosseous implants. Biomaterials 2006;27:926-36. doi:10.1016/j.biomaterials.2005.07.009.

[17] Oliva J, Oliva X, Oliva JD. Five-year success rate of 831 consecutively placed Zirconia dental implants in humans: a comparison of three different rough surfaces. Int J Oral Maxillofac Implants 2010;25:336-44.

[18] Flamant Q, Anglada M. Hydrofluoric acid etching of dental zirconia. Part 2: effect on flexural strength and ageing behavior. n.d.

[19] Muñoz-Tabares J a., Jiménez-Piqué E, Anglada MJ. Subsurface evaluation of hydrothermal degradation of zirconia. Acta Mater 2011;59:473-84. doi:10.1016/j.actamat.2010.09.047.

[20] Dong W, Sullivan P, Stout K. Comprehensive study of parameters for characterising three- dimensional surface topographyIII: Parameters for characterising amplitude and some functional properties. Wear 1994;178:29-43. doi:10.1016/0043-1648(94)90127-9.

[21] Dong WP, Sullivan PJ, Stout KJ. Comprehensive study of parameters for characterising three-dimensional surface topography: IV: Parameters for characterising spatial and hybrid properties. Wear 1994;178:45-60.

[22] Stout KJ, Blunt L. Three Dimensional Surface Topography. Elsevier; 2000. doi:10.1016/B978-185718026-8/50119-3.

[23] Brown C a., Charles PD, Johnsen W a., Chesters S. Fractal analysis of topographic data by the patchwork method. Wear 1993;161:61-7. doi:10.1016/0043-1648(93)90453-S.

[24] Siegmann S. Scale-Sensitive Fractal Analysis for Understanding the Influence of Substrate Roughness in Thermal Spraying. 1st United Therm. Spray Conf. Therm. Spray A United Forum Sci. Technol. Adv., 1997, p. 665-70. 
[25] Nefedov VI, Sergushin NP, Band IM, Trzhaskovskaya MB. Relative intensities in X-ray photoelectron spectra. J Electron Spectros Relat Phenomena 1973;2:383-403.

[26] Wagner CD. Handbook of x-ray photoelectron spectroscopy: a reference book of standard data for use in x-ray photoelectron spectroscopy. Physical Electronics Division, Perkin-Elmer Corp.; 1979.

[27] Majumdar D, Chatterjee D. X-ray photoelectron spectroscopic studies on yttria, zirconia, and yttria-stabilized zirconia. J Appl Phys 1991;70:988. doi:10.1063/1.349611.

[28] Kaufmann R, Klewe-Nebenius H, Moers H, Pfennig G, Jenett H, Ache HJ. XPS studies of the thermal behaviour of passivated Zircaloy-4 surfaces. Surf Interface Anal 1988;11:502-9. doi:10.1002/sia.740111003.

[29] Baschenko OA, Nefedov VI. Relative intensities in X-ray photoelectron spectra: Part IV. The effect of elastic scattering in a solid on the free path of electrons and their angular distribution. J Electron Spectros Relat Phenomena 1979;17:405-20.

[30] Barr TL. An ESCA study of the termination of the passivation of elemental metals. J Phys Chem 1978;82:1801-10. doi:10.1021/j100505a006.

[31] Robbins H, Schwartz B. Chemical Etching of Silicon. J Electrochem Soc 1959;106:505. doi:10.1149/1.2427397.

[32] Shah IA, van der Wolf BMA, van Enckevort WJP, Vlieg E. Wet Chemical Etching of Silicon $\{111\}$ : Autocatalysis in Pit Formation. J Electrochem Soc 2008;155:J79. doi:10.1149/1.2830841.

[33] Sasaki T, Nakaoka O, Arakawa R, Kobayashi T, Takagi I, Moriyama H. Detection of Polynuclear Zirconium Hydroxide Species in Aqueous Solution by Desktop ESI-MS. J Nucl Sci Technol 2010;47:1211-8. doi:10.1080/18811248.2010.9720988.

[34] Xu X, Ling L, Ding X, Burgess JO. Synthesis and characterization of a novel, fluoride-releasing dimethacrylate monomer and its dental composite. J Polym Sci Part A Polym Chem 2004;42:985-98. doi:10.1002/pola.11037.

[35] Xu X, Ding X, Ling L, Burgess JO. Synthesis and characterization of novel fluoride-releasing monomers. II. Dimethacrylates containing bis(aminodiacetic acid) and their ternary zirconium fluoride complexes. J Polym Sci Part A Polym Chem 2005;43:3153-66. doi:10.1002/pola.20787.

[36] Qian L, Zai J, Chen Z, Zhu J, Yuan Y, Qian X. Control of the morphology and composition of yttrium fluoridevia a salt-assisted hydrothermal method. CrystEngComm 2010;12:199-206. doi:10.1039/B911401G. 
[37] Lowalekar V, Raghavan S. Etching of Zirconium Oxide, Hafnium Oxide, and Hafnium Silicates in Dilute Hydrofluoric Acid Solutions. J Mater Res 2004;19:1149-56. doi:10.1557/JMR.2004.0149.

[38] Zinger O, Anselme K, Denzer a, Habersetzer P, Wieland M, Jeanfils J, et al. Time-dependent morphology and adhesion of osteoblastic cells on titanium model surfaces featuring scale-resolved topography. Biomaterials 2004;25:2695711. doi:10.1016/j.biomaterials.2003.09.111.

[39] Kunzler TP, Drobek T, Schuler M, Spencer ND. Systematic study of osteoblast and fibroblast response to roughness by means of surface-morphology gradients. Biomaterials 2007;28:2175-82. doi:10.1016/j.biomaterials.2007.01.019.

[40] Davies JE, Ajami E, Moineddin R, Mendes VC. The roles of different scale ranges of surface implant topography on the stability of the bone/implant interface. Biomaterials 2013;34:3535-46. doi:10.1016/j.biomaterials.2013.01.024.

[41] Gittens R a, Olivares-Navarrete R, Schwartz Z, Boyan BD. Implant osseointegration and the role of microroughness and nanostructures: Lessons for spine implants. Acta Biomater 2014;10:3363-71. doi:10.1016/j.actbio.2014.03.037.

[42] Svanborg LM, Andersson M, Wennerberg A. Surface characterization of commercial oral implants on the nanometer level. J Biomed Mater Res B Appl Biomater 2010;92:462-9. doi:10.1002/jbm.b.31538.

[43] Wennerberg A, Albrektsson T. Effects of titanium surface topography on bone integration: a systematic review. Clin Oral Implants Res 2009;20 Suppl 4:17284. doi:10.1111/j.1600-0501.2009.01775.x.

[44] Zinelis S, Thomas a, Syres K, Silikas N, Eliades G. Surface characterization of zirconia dental implants. Dent Mater 2010;26:295-305. doi:10.1016/j.dental.2009.11.079. 